\title{
Development of collection and unloading unit attachment for self propelled vertical conveyor reaper
}

A.V. GAJAKOS, R.S. GAIKWAD AND V.V. SARAF

Received : 15.11.2014; Revised : 13.03.2015; Accepted : 24.03.2015

See end of the Paper for authors' affiliation

Correspondence to :

V.V. SARAF

Department of Farm Power and Machinery, Dr. Panjabrao Deshmukh Krishi Vidyapeeth, AKOLA (M.S.) INDIA

Email : avgajakos@gmail.com
-ABSTRACT : The self propelled vertical conveyor reaper for soybean crop was undertaken for modification with the objectives to develop collection and unloading unit attachment for self propelled vertical conveyor reaper for harvesting of soybean crop. The developed unit consists of collection box, unloading unit and ground wheel. In manual harvesting of soybean crop, the crop after harvesting, is collected at one place and stored in the heap form for further threshing. This process of collection and heap making is very laborious and drudgerious. In the view, the self propelled vertical conveyor reaper (SPVCR) was tested for its field performance for harvesting of soybean crop. Based on the field tests, a work of development of collection and unloading unit attachment for SPVCR was carried out. The unit was developed for collection and unloading of harvested soybean crop at every $5 \mathrm{~m}$ distance of travel. The effective field capacity of SPVCR was found to be $0.255 \mathrm{ha} / \mathrm{hr}$ with field efficiency of 88.78 per cent. The cost operation was $773.78 \mathrm{Rs} . /$ hr. Laboratory trials of unit were conducted and found satisfactory. Also the test results of mechanical harvesting of soybean crop by SPVCR were compared with test results of manual harvesting for to determine the benefits of mechanical harvesting over manual harvesting. The SPVCR cut and windrowed cut crop of soybean uniformly in a row. Fuel consumption of SPVCR was 2.81 lt./ha. The average harvesting losses in mechanical harvesting and manual harvesting were found to be 3.55 per cent and 3.42 per cent, respectively.

— KEY WORDS : Power unit, Transmission unit, Reaping, Conveying unit, Collection, Unloading unit

- HOW TO CITE THIS PAPER : Gajakos, A.V., Gaikwad, R.S. and Saraf, V.V. (2015). Development of collection and unloading unit attachment for self propelled vertical conveyor reaper. Internat. J. Agric. Engg., 8(1) : 121-126. 